\title{
Cosmic Ray Induced Photodestruction of Interstellar Molecules
}

\author{
R. Gredel ${ }^{1,2}$, S. Lepp ${ }^{1}$, A. Dalgarno ${ }^{1}$ and E. Herbst ${ }^{3}$ \\ ${ }^{1}$ Harvard-Smithsonian Center for Astrophysics; ${ }^{2}$ European Southern \\ Observatory; ${ }^{3}$ Department of Physics, Duke University
}

\section{ABSTRACT}

Ultraviolet photons are created in the interior of dense interstellar clouds by the impact excitation of molecular hydrogen by secondary electrons generated by cosmic ray ionization. The resulting photodissociation and photoionization rates of a wide range of interstellar molecules are calculated. The effects on the equilibrium chemical composition of dense clouds are briefly discussed.

\section{Introduction}

The interior of a dense molecular cloud is efficiently shielded from the ultraviolet photons of the interstellar radiation field by the grains. Accordingly, the effects of the UV photons on the physical and chemical state of a dense cloud are in general neglected. However, internal sources of UV photons may be present, such as young stars or shocks from mass losing young stars. Here the discussion is focused on a diffuse source of UV photons arising from $\mathrm{H}_{2}$ emission. In dense molecular clouds, cosmic rays with energies between 10 and $100 \mathrm{MeV}$ ionize $\mathrm{H}_{2}$ and generate secondary electrons with a mean energy around $30 \mathrm{eV}$ (Cravens and Dalgarno 1978). Because the fractional ionization is generally low, the electrons lose their energy mainly by exciting, dissociating and ionizing $\mathrm{H}_{2}$. The subsequent decay of the electronically excited states of $\mathrm{H}_{2}$ produces UV photons within the clouds.

The idea of molecular hydrogen emission was invoked by Prasad and Tarafdar (1983) to explain the large abundance of atomic carbon which exists in several molecular clouds. In their mechanism, $\mathrm{CO}$ is photodissociated

$$
\mathrm{CO}+\mathrm{h} \nu \rightarrow \mathrm{C}+\mathrm{O}
$$

by the internal photons. The influence of the UV photons on the abundances of interstellar molecules has been explored by Sternberg, Dalgarno and Lepp (1987) who took into account the photons created by the excitation of the $\mathrm{B}{ }^{1} \Sigma_{\mathrm{u}}^{+}$and $\mathrm{C}^{1} \Pi_{\mathrm{u}}$ states of molecular hydrogen. A more complete description of the cosmic ray induced ultraviolet spectrum involving excitation to other singlet and triplet states of $\mathrm{H}_{2}$ has been given by Gredel, Lepp and Dalgarno (1987) who employed it in a calculation of the photodissociation rate of $\mathrm{CO}$. We use their spectrum to derive the internal photodissociation rates of a wide range of interstellar molecules for which photodissociation cross sections are available. We briefly discuss the effects on the equilibrium chemical composition of dense clouds, extending the models of Sternberg et al. (1987). 


\section{The ultraviolet spectrum of $\mathrm{H}_{2}$}

The collisional excitation of rotation-vibration levels in the various electronic states of $\mathrm{H}_{2}$ by the secondary electrons lead to the emission of ultraviolet photons in the $100-$ $200 \mathrm{~nm}$ range. The energy degradation process of the secondary electrons was calculated following the method used by Cravens, Victor and Dalgarno (1975). Excitations to the B ${ }^{1} \Sigma_{\mathrm{u}}^{+}, \mathrm{B}^{\prime}{ }^{1} \Sigma_{\mathrm{u}}^{+}, \mathrm{B}^{\prime 1}{ }^{1} \Sigma_{\mathrm{u}}^{+}, \mathrm{C}^{1} \Pi_{\mathrm{u}}, \mathrm{D}^{1} \Pi_{\mathrm{u}}$ and $\mathrm{D}^{\prime}{ }^{1} \Pi_{\mathrm{u}}$ Rydberg states and to the valence $\mathrm{E}, \mathrm{F}^{1} \Sigma_{\mathrm{g}}^{+}$and $\mathrm{a}^{3} \Sigma_{\mathrm{g}}^{+}$states were included together with excitations into the repulsive $b^{3} \Sigma_{\mathbf{u}}^{+}$state and into vibrational levels of the ground state. The energy loss of the injected electrons can be expressed in terms of the number of excitations, $\epsilon_{\mathrm{i}}\left(\mathrm{v}^{\prime}\right)$ of vibrational levels $\mathrm{v}^{\prime}$ of the various electronic states $\mathrm{i}$. In terms of $\epsilon_{\mathrm{i}}\left(\mathrm{v}^{\prime}\right)$, the probability $\mathrm{P}_{\mathrm{i}}(\nu)$ for the emission of a photon of frequency $\nu$ resulting from the radiative decay out of a particular level $\left(i v^{\prime} J^{\prime}\right)$ to a lower level $\left(j v^{\prime \prime} J^{\prime \prime}\right)$ is given by

$$
\mathrm{P}_{\mathrm{i}}(\nu)=\sum_{\mathrm{J}_{0}} \frac{\epsilon_{\mathrm{i}}\left(\mathrm{v}^{\prime}\right) \mathrm{S}_{\mathrm{J}^{\prime}, \mathrm{J}_{0}}}{\sum_{\mathrm{v}^{\prime}, \mathrm{J}^{\prime}} \epsilon_{\mathrm{i}}\left(\mathrm{v}^{\prime}\right) \mathrm{S}_{\mathrm{J}^{\prime}, \mathrm{J}_{0}}} \times \frac{\mathrm{A}_{\mathrm{v}^{\prime} \mathrm{J}^{\prime}, \mathrm{v}^{\prime \prime} \mathrm{J}^{\prime \prime}}}{\mathrm{A}_{\mathrm{v}^{\prime} \mathrm{J}^{\prime}}} \times \omega_{\mathrm{J}_{0}}
$$

where the first term is the probability of the excitation of the rotational level $v^{\prime} J^{\prime}$ in $i$, $S_{\mathrm{J}^{\prime}, \mathrm{J}_{0}}$ is the Hönl - London factor and $J_{0}$ is the initial rotational level in the $\mathrm{v}^{\prime \prime}=0$ level of the ground state of $\mathrm{H}_{2}$. The second term is the branching ratio describing the probability that the particular transition $\mathrm{v}^{\prime} \mathrm{J}^{\prime} \rightarrow \mathrm{v}^{\prime \prime} \mathrm{J}^{\prime \prime}$ occurs, $\nu$ is the transition frequency, the weight $\omega_{J_{0}}$ is the fractional population of $\mathrm{H}_{2}$ in the initial rotational level $\mathrm{J}_{0}$ and $A_{\mathrm{v}^{\prime}} \mathrm{J}^{\prime}$ is the total transition probability for emission from level $\mathrm{v}^{\prime} \mathrm{J}^{\prime}$.

The vibrational levels in the higher-lying Rydberg states predissociate. Vibrational levels $\mathrm{v}^{\prime}>0$ in the $\mathrm{B}^{\prime \prime}{ }^{1} \Sigma_{\mathrm{u}}^{+}$state and $\mathrm{v}^{\prime}>3$ in the $\mathrm{D}^{\prime}{ }^{1} \Pi_{\mathrm{u}}$ state strongly predissociate with efficiencies $\eta$ near unity (Ajello et al. 1984). In the $\mathrm{D}^{1} \Pi_{u}$ state, levels $\mathrm{v}^{\prime}=$ $3-8$ have predissociation efficiencies around 0.5 (Ajello et al. 1984). For them (1$\left.\eta_{\mathrm{i}}\left(\mathrm{v}^{\prime}\right)\right)$ was included in eq. (2) as an additional factor. We calculated the corresponding fluorescence efficiencies $\mathrm{P}_{\mathrm{i}}(\nu)$ for the $\mathrm{D}^{1} \Pi_{\mathrm{u}}-\mathrm{X}^{1} \Sigma_{\mathrm{g}}^{+}, \mathrm{D}^{\prime}{ }^{1} \Pi_{\mathrm{u}}-\mathrm{X}^{1} \Sigma_{\mathrm{g}}^{+}$and $\mathrm{B}^{\prime 1}{ }^{1} \Sigma_{\mathrm{u}}^{+}-$ $\mathrm{X}^{1} \Sigma_{\mathrm{g}}^{+}$transitions to be $0.7,0.4$ and 0.07 respectively, in close agreement with those of Ajello et al. (1984).

The resulting spectrum was obtained for a neutral gas of $\mathrm{H}_{2}$ by summing the probabilities for photon emission from the various electronic states $i$, weighted with the total excitation rate $\epsilon_{\mathrm{i}}$, according to

$$
\mathrm{P}(\nu)=\sum_{\mathrm{i}} \mathrm{P}_{\mathrm{i}}(\nu) \times \epsilon_{\mathrm{i}} / \mathrm{R}_{\mathrm{I}}
$$

where $\epsilon_{\mathrm{i}}=\sum_{\mathrm{v}^{\prime}} \epsilon_{\mathrm{i}}\left(\mathrm{v}^{\prime}\right)$ and $\mathrm{R}_{\mathrm{I}}$ is the total number of ionizations. The emission spectrum depends in detail on the rotational populations of the hydrogen molecules, but with the exception of $\mathrm{CO}$, the resulting photodissociation and photoionization rates are little affected. We present in Figure 1 the emission spectrum for a rotational population in which the molecules are shared between the $J=0$ and 1 levels in the ratio $1: 3$. It is shown distributed in bins of $0.1 \mathrm{~nm}$. The spectrum consists of numerous discrete lines superimposed on continuum emission from transitions into the vibrational continuum of the ground state and from the $\mathrm{a}^{3} \Sigma_{\mathrm{g}}^{+}-\mathrm{b}^{3} \Sigma_{\mathrm{u}}^{+}$transition. 


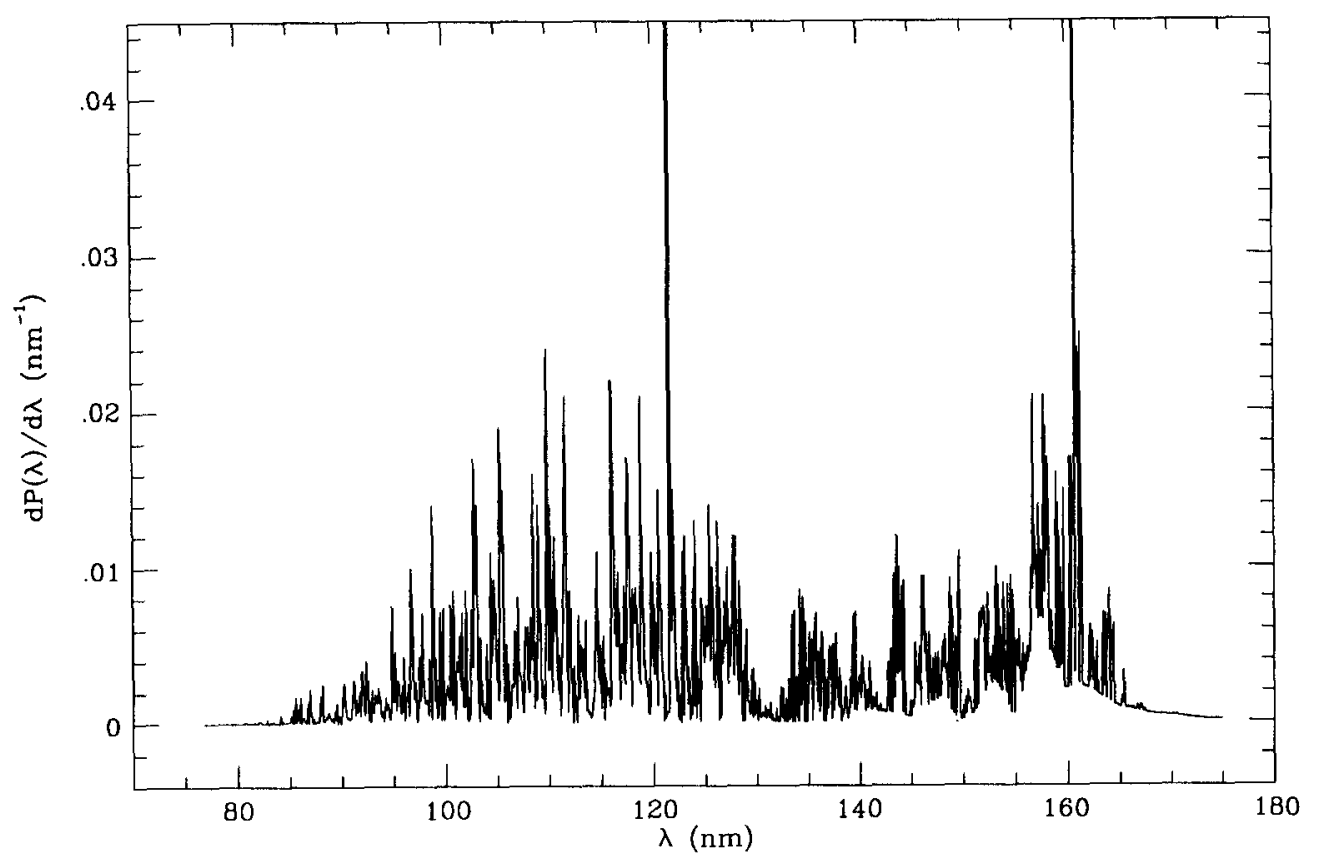

Fig. 1. The emission spectrum of $\mathrm{H}_{2}$ between $75 \mathrm{~nm}$ and $175 \mathrm{~nm}$ shown as number of photons emitted per $\mathrm{nm}$. The lines connect the points at intervals of $0.1 \mathrm{~nm}$, each point representing the emission lines falling into the $0.1 \mathrm{~nm}$ bin and the continuum emission integrated over the bin.

\section{Photodestruction of Interstellar Molecules}

The photodissociation and photoionization rate $R_{M}$ of a molecular species $M$ with density $\mathrm{n}(\mathrm{M})$ corresponding to a total cosmic ray ionization rate of $\zeta \mathrm{s}^{-1}$ is given by

$$
\mathrm{R}_{\mathrm{M}}=\zeta \mathrm{n}(\mathrm{M}) \int \frac{\sigma_{\mathrm{M}}(\nu) \mathrm{P}(\nu)}{\sigma_{\text {tot }}(\nu)} \mathrm{d} \nu
$$

$\mathrm{P}(\nu)$ is the probability for the emission of a photon at frequency $\nu$ as given in eq. (3). $\sigma_{\mathrm{M}}(\nu)$ is the photodissociation or photoionization cross section and $\sigma_{\text {tot }}(\nu)$ is the total absorption cross section. It may be written in the form

$$
\sigma_{\text {tot }}(\nu)=\sigma_{\mathfrak{g}}(1-\omega)+\sum_{\mathbf{M}^{\prime}} \kappa_{M^{\prime}} \sigma_{\mathbb{M}^{\prime}}(\nu)
$$

where $\sigma_{\mathrm{g}}=2 \times 10^{-21} \mathrm{~cm}^{-2}$ is the grain extinction cross section per hydrogen nucleus, $\omega$ is the grain albedo and $\kappa_{M}=n(M) / n_{H}$. In practice, for molecules in interstellar clouds, 
with the exception of $\mathrm{CO}$ (Gredel et al. 1987), $\sigma_{\text {tot }}$ is dominated by $\sigma_{\mathrm{g}}(1-\omega)$ and for them we may write

$$
\mathrm{R}_{\mathrm{M}}=\frac{\zeta \mathrm{n}(\mathrm{M})}{(1-\omega)} \mathrm{p} \mathrm{cm}^{-3} \mathrm{~s}^{-1}
$$

where the efficiency $\mathrm{p}$ is given by

$$
\mathrm{p}=\int \frac{\sigma_{\mathrm{M}}(\nu) \mathrm{P}(\nu)}{\sigma_{\mathrm{g}}} \mathrm{d} \nu .
$$

The cosmic ray induced photodestruction efficiencies of 37 molecules are presented in Table 1. It includes most interstellar molecules for which at least some data on the absorption cross sections in the ultraviolet are available. For several species, there are no experimental data and theoretical values of the photoabsorption cross sections were adopted. For many molecules the data are fragmentary, especially as regards the identity of the dissociation products. The available data often refer to total absorption and in such cases we have made arbitrary estimates of the probabilities of the dissociation.

\begin{tabular}{|c|c|c|c|c|c|c|c|}
\hline & \multicolumn{2}{|c|}{ Reaction } & \multirow{2}{*}{$\frac{\mathrm{p}}{237}$} & \multicolumn{3}{|c|}{ Reaction } & \multirow{2}{*}{$\frac{\mathrm{p}}{730}$} \\
\hline $\mathrm{C}_{2}$ & $\rightarrow$ & $\mathrm{C}+\mathrm{C}$ & & $\mathrm{CH}$ & $\rightarrow$ & $\mathrm{C}+\mathrm{H}$ & \\
\hline $\mathrm{CH}^{+}$ & $\rightarrow$ & $\mathrm{C}+\mathrm{H}^{+}$ & 176 & $\mathrm{CN}$ & $\rightarrow$ & $\mathrm{C}+\mathrm{N}$ & 10580 \\
\hline $\mathrm{OH}$ & $\rightarrow$ & $\mathrm{O}+\mathrm{H}$ & 509 & $\mathrm{O}_{2}$ & $\rightarrow$ & $\mathrm{O}+\mathrm{O}$ & 751 \\
\hline $\mathrm{O}_{2}$ & $\rightarrow$ & $\mathrm{O}_{2}^{+}+\mathrm{e}$ & 117 & $\mathrm{NO}$ & $\rightarrow$ & $\mathrm{N}+\mathrm{O}$ & 482 \\
\hline NO & & $\mathrm{NO}^{+}+\mathrm{e}$ & 494 & $\mathrm{HCl}$ & $\rightarrow$ & $\mathrm{H}+\mathrm{Cl}$ & 610 \\
\hline $\mathrm{H}_{2} \mathrm{O}$ & $\rightarrow$ & $\mathrm{H}+\mathrm{OH}$ & 971 & $\mathrm{CO}_{2}$ & $\rightarrow$ & $\mathrm{CO}+\mathrm{O}$ & 1708 \\
\hline $\mathrm{CO}_{2}$ & $\rightarrow$ & $\mathrm{CO}_{2}^{+}+\mathrm{e}$ & 0 & $\mathrm{H}_{3}^{+}$ & $\rightarrow$ & $2 \mathrm{H}+\mathrm{H}^{+}$ & $<1$ \\
\hline $\mathrm{HCN}$ & $\rightarrow$ & $\mathrm{CN}+\mathrm{H}$ & 3114 & $\mathrm{HCO}$ & $\rightarrow$ & $\mathrm{H}+\mathrm{CO}$ & 421 \\
\hline $\mathrm{HCO}$ & & $\mathrm{HCO}^{+}+\mathrm{e}$ & 1169 & OCS & $\rightarrow$ & $\mathrm{CO}+\mathrm{S}$ & 5360 \\
\hline OCS & $\rightarrow$ & $\mathrm{OCS}^{+}+\mathrm{e}$ & 1444 & $\mathrm{C}_{3}$ & $\rightarrow$ & $\mathrm{C}_{2}+\mathrm{C}$ & 1119 \\
\hline $\mathrm{H}_{2} \mathrm{~S}$ & $\rightarrow$ & $\mathrm{H}_{2}+\mathrm{S}$ & 5154 & $\mathrm{H}_{2} \mathrm{~S}$ & $\rightarrow$ & $\mathrm{H}_{2} \mathrm{~S}^{+}+e$ & 1696 \\
\hline $\mathrm{SO}_{2}$ & $\rightarrow$ & $\mathrm{SO}+\mathrm{O}$ & 1884 & $\mathrm{NH}_{2}$ & $\rightarrow$ & $\mathrm{NH}+\mathrm{H}$ & 80 \\
\hline $\mathrm{NH}_{2}$ & $\rightarrow$ & $\mathrm{NH}_{2}^{+}+\mathrm{e}$ & 649 & $\mathrm{NH}_{3}$ & $\rightarrow$ & $\mathrm{NH}_{2}+\mathrm{H}$ & 1315 \\
\hline $\mathrm{NH}_{3}$ & $\rightarrow$ & $\mathrm{NH}+\mathrm{H}_{2}$ & 541 & $\mathrm{NH}_{3}$ & $\rightarrow$ & $\mathrm{NH}_{3}^{+}+\mathrm{e}$ & 576 \\
\hline $\mathrm{CH}_{2} \mathrm{O}_{2}$ & $\rightarrow$ & $\mathrm{CH}_{2} \mathrm{O}_{2}^{+}+\mathrm{e}$ & 649 & $\mathrm{CH}_{2} \mathrm{O}_{2}$ & $\rightarrow$ & $\mathrm{HCO}+\mathrm{OH}$ & 249 \\
\hline $\mathrm{CH}_{3} \mathrm{~N}$ & $\rightarrow$ & $\mathrm{HCN}+\mathrm{H}_{2}$ & 4982 & $\mathrm{CH}_{4}$ & $\rightarrow$ & $\mathrm{CH}_{2}+\mathrm{H}_{2}$ & 2339 \\
\hline $\mathrm{CH}_{4} \mathrm{O}$ & $\rightarrow$ & $\mathrm{H}_{2} \mathrm{CO}+\mathrm{H}_{2}$ & 3168 & $\mathrm{CH}_{4} \mathrm{O}$ & $\rightarrow$ & $\mathrm{CH}_{3}+\mathrm{OH}$ & 1504 \\
\hline $\mathrm{CH}_{4} \mathrm{O}$ & $\rightarrow$ & $\mathrm{CH}_{4} \mathrm{O}^{+}+\mathrm{e}$ & 1433 & $\mathrm{CH}_{4} \mathrm{O}$ & $\rightarrow$ & $\mathrm{CH}_{3} \mathrm{O}^{+}+\mathrm{H}+\mathrm{e}$ & 99 \\
\hline $\mathrm{CH}_{5} \mathrm{~N}$ & $\rightarrow$ & $\mathrm{HCN}+\mathrm{H}_{2}+2 \mathrm{H}$ & 1409 & $\mathrm{CH}_{5} \mathrm{~N}$ & $\rightarrow$ & $\mathrm{CH}_{3} \mathrm{~N}+2 \mathrm{H}$ & 19 \\
\hline $\mathrm{CH}_{5} \mathrm{~N}$ & $\rightarrow$ & $\mathrm{CH}_{3}+\mathrm{NH}_{2}$ & 670 & $\mathrm{CH}_{5} \mathrm{~N}$ & $\rightarrow$ & $\mathrm{CN}+2 \mathrm{H}_{2}+\mathrm{H}$ & 367 \\
\hline $\mathrm{CH}_{5} \mathrm{~N}$ & $\rightarrow$ & $\mathrm{CH}_{5} \mathrm{~N}^{+}+\mathrm{e}$ & 1119 & $\mathrm{C}_{2} \mathrm{H}_{2}$ & $\rightarrow$ & $\mathrm{C}_{2} \mathrm{H}+\mathrm{H}$ & 5155 \\
\hline $\mathrm{C}_{2} \mathrm{H}_{2}$ & $\rightarrow$ & $\mathrm{C}_{2} \mathrm{H}_{2}^{+}+\mathrm{e}$ & 1309 & $\mathrm{C}_{2} \mathrm{H}_{2} \mathrm{O}$ & $\rightarrow$ & $\mathrm{CH}_{2}+\mathrm{CO}$ & 913 \\
\hline $\mathrm{C}_{2} \mathrm{H}_{2} \mathrm{O}$ & $\rightarrow$ & $\mathrm{C}_{2} \mathrm{H}_{2} \mathrm{O}^{+}+\mathrm{e}$ & 1218 & $\mathrm{C}_{2} \mathrm{H}_{3} \mathrm{~N}$ & $\rightarrow$ & $\mathrm{CH}_{3}+\mathrm{CN}$ & 4756 \\
\hline $\mathrm{C}_{2} \mathrm{H}_{3} \mathrm{~N}$ & $\rightarrow$ & $\mathrm{C}_{2} \mathrm{H}_{3} \mathrm{~N}^{+}+\mathrm{e}$ & 2245 & $\mathrm{C}_{2} \mathrm{H}_{4}$ & $\rightarrow$ & $\mathrm{C}_{2} \mathrm{H}_{2}+\mathrm{H}_{2}$ & 3700 \\
\hline $\mathrm{C}_{2} \mathrm{H}_{4}$ & $\rightarrow$ & $\mathrm{C}_{2} \mathrm{H}_{4}^{+}+\mathrm{e}$ & 778 & $\mathrm{C}_{2} \mathrm{H}_{4} \mathrm{O}$ & $\rightarrow$ & $\mathrm{CH}_{3}+\mathrm{CHO}$ & 527 \\
\hline $\mathrm{C}_{2} \mathrm{H}_{4} \mathrm{O}$ & $\rightarrow$ & $\mathrm{C}_{2} \mathrm{H}_{4} \mathrm{O}^{+}+\mathrm{e}$ & 1119 & $\mathrm{CH}_{3} \mathrm{OCH}_{3}$ & & $\mathrm{H}_{2} \mathrm{CO}+\mathrm{CH}_{4}$ & 1714 \\
\hline
\end{tabular}

Table 1. Cosmic ray induced photodissociation and photoionization efficiencies p of interstellar molecules 
Table 1. continued

\begin{tabular}{|c|c|c|c|c|c|c|c|}
\hline \multicolumn{3}{|c|}{ Reaction } & \multirow{2}{*}{$\frac{p}{1119}$} & \multicolumn{3}{|c|}{ Reaction } & \multirow{2}{*}{$\frac{p}{4307}$} \\
\hline $\mathrm{CH}_{3} \mathrm{OCH}_{3}$ & & $\mathrm{C}_{2} \mathrm{H}_{6} \mathrm{O}^{+}+\mathrm{e}$ & & $\mathrm{C}_{2} \mathrm{H}_{5} \mathrm{OH}$ & $\rightarrow$ & $\mathrm{C}_{2} \mathrm{H}_{5}+\mathrm{OH}$ & \\
\hline $\mathrm{C}_{2} \mathrm{H}_{5} \mathrm{OH}$ & $\rightarrow$ & $\mathrm{C}_{2} \mathrm{H}_{5} \mathrm{OH}^{+}+\mathrm{e}$ & 2736 & $\mathrm{C}_{3} \mathrm{HN}$ & $\rightarrow$ & $\mathrm{C}_{2} \mathrm{H}+\mathrm{CN}$ & 1727 \\
\hline $\mathrm{C}_{3} \mathrm{H}_{4}$ & $\rightarrow$ & $\mathrm{C}_{3} \mathrm{H}_{3}+\mathrm{H}$ & 3284 & $\mathrm{C}_{3} \mathrm{H}_{4}$ & $\rightarrow$ & $\mathrm{C}_{3} \mathrm{H}_{4}^{+}+e$ & 5305 \\
\hline $\mathrm{C}_{3} \mathrm{O}$ & $\rightarrow$ & $\mathrm{C}_{2}+\mathrm{CO}$ & 6609 & $\mathrm{C}_{4} \mathrm{H}_{2}$ & $\rightarrow$ & $\mathrm{C}_{4} \mathrm{H}+\mathrm{H}$ & 1730 \\
\hline $\mathrm{C}_{4} \mathrm{H}_{2}$ & $\rightarrow$ & $2 \mathrm{C}_{2} \mathrm{H}$ & 1730 & $\mathrm{C}_{4} \mathrm{H}_{2}$ & $\rightarrow$ & $\mathrm{C}_{4} \mathrm{H}_{2}^{+}+e$ & 1119 \\
\hline $\mathrm{H}_{2} \mathrm{CO}$ & $\rightarrow$ & $\mathrm{CO}+\mathrm{H}_{2}$ & 2659 & $\mathrm{HNCO}$ & $\rightarrow$ & $\mathrm{NH}+\mathrm{CO}$ & 2361 \\
\hline
\end{tabular}

\section{The Steady State Abundances of Interstellar Molecules}

We briefly explore the effects of the cosmic ray induced photons on the abundances of interstellar molecules, using a version of the chemistry of Sternberg et al. (1987), modified by the incorporation of the rate coefficients of dissociative recombination recommended by Bates (1986, 1987) and Millar, DeFrees, McLean and Herbst (1988). We present results for a uniform cloud of total hydrogen density $n_{\mathrm{H}}=10^{4} \mathrm{~cm}^{-3}$, a temperature of $50 \mathrm{~K}$, abundances relative to $\mathrm{H}_{2}$ for carbon of $1.46 \times 10^{-4}$, for oxygen of $3.52 \times 10^{-4}$ and for nitrogen of $4.5 \times 10^{-5}$, a cosmic ray ionization rate of $\zeta=10^{-17} \mathrm{~s}^{-1}$, a total metal abundance ratio relative to hydrogen of $1.5 \times 10^{-8}$ and an albedo $\omega$ of 0.5 .

Table 2. Fractional Abundances $n(M) / n_{H}$ at Steady State

\begin{tabular}{lllll}
\hline & $(\mathrm{a})$ & $(\mathrm{b})$ & $(\mathrm{c})$ & $(\mathrm{d})$ \\
\hline \hline $\mathrm{O}$ & $7.9(-5)$ & $1.2(-4)$ & $1.2(-4)$ & $1.1(-4)$ \\
$\mathrm{OH}$ & $3.3(-9)$ & $1.4(-8)$ & $1.3(-8)$ & $1.4(-8)$ \\
$\mathrm{H}_{2} \mathrm{O}$ & $5.4(-5)$ & $2.5(-5)$ & $2.5(-5)$ & $2.5(-5)$ \\
$\mathrm{O}_{2}$ & $3.7(-5)$ & $3.1(-5)$ & $3.0(-5)$ & $3.3(-5)$ \\
$\mathrm{C}^{+}$ & $1.8(-10)$ & $4.3(-10)$ & $4.4(-10)$ & $4.2(-10)$ \\
$\mathrm{C}$ & $4.5(-9)$ & $6.5(-9)$ & $6.1(-7)$ & $7.9(-7)$ \\
$\mathrm{C}_{2} \mathrm{H}_{2}$ & $4.2(-9)$ & $7.2(-11)$ & $7.5(-10)$ & $1.9(-9)$ \\
$\mathrm{CH}_{4}$ & $6.6(-8)$ & $9.6(-9)$ & $9.5(-8)$ & $1.7(-7)$ \\
$\mathrm{C}_{2} \mathrm{H}$ & $1.5(-10)$ & $4.2(-11)$ & $4.2(-10)$ & $8.3(-10)$ \\
$\mathrm{C}_{3} \mathrm{H}_{2}$ & $2.1(-11)$ & $8.8(-13)$ & $9.4(-12)$ & $1.2(-12)$ \\
$\mathrm{NH}_{3}$ & $4.7(-8)$ & $4.4(-8)$ & $4.1(-8)$ & $3.3(-8)$ \\
$\mathrm{HCN}$ & $1.9(-10)$ & $2.7(-10)$ & $1.2(-9)$ & $6.0(-10)$ \\
\hline
\end{tabular}
(a) no photons, no LM
(b) photons but no photodissociation of CO, no LM
(c) photons, no LM
(d) photons, $\mathrm{LM}$ at $\mathrm{n}(\mathrm{LM}) / \mathrm{n}(\mathrm{H})=10^{-7}$ 
In the first two columns of Table 2, we show the effects on the steady-state abundances including cosmic ray induced photodissociation and photoionization, but ignoring the photodissociation of $\mathrm{CO}$. The inclusion of the photon field severely diminishes the steady-state abundances of the more complex species because photodissociation is an effective destruction process at many points in the formation sequence (Sternberg et al. 1987).

The destructive effects are mitigated when the photodissociation of $\mathrm{CO}$ is included, as the third column of Table 2 demonstrates. The additional source of neutral carbon enhances the supply of complex hydrocarbons. Large molecules, if they exist in significant amounts in dense interstellar clouds, also enhance the abundances of the complex hydrocarbons (Lepp and Dalgarno 1988). The addition of a large molecule component with an abundance relative to hydrogen of $10^{-7}$ yields in our model chemistry the steady state concentrations given in column 4 of Table 2 . With the inclusion of the photodissociation of $\mathrm{CO}$ as a source of neutral carbon, the additional source from charge transfer to large molecules and mutual neutralization to large molecular negative ions (Lepp and Dalgarno 1988) has but small consequences.

Because the time scales of the internal photodestruction processes are longer than the time scales to form molecules, the maximum abundances are not significantly affected by the presence of the internally generated photons.

\section{References}

Ajello, J.M., Shemansky, D.E., Kwok, T.L., and Yung, Y.L. 1984,Phys. Rev. 29, 636. Bates, D.R. 1986, Astrophys. J. Letters 306, L45.

Bates, D.R., 1987, Recent Studies in Atomic and Molecular Processes, ed. A.E. Kingston (Plenum Press).

Cravens, T., and Dalgarno, A. 1978, Astrophys. J. 219, 750.

Cravens, T., Victor, G.A., and Dalgarno, A. 1975, Planet Spa. Sci. 23, 1059.

Gredel, R., Dalgarno, A., and Lepp, S. 1987, Astrophys. J. Letters 323, L137.

Lepp, S., and Dalgarno, A. 1988, Astrophys. J. 324, 553.

Prasad, S.S., and Tarafdar, S.P. 1983, Astrophys. J. 267, 603.

Millar, T.J., DeFrees, D.J., McLean, A.D., and Herbst, E. 1988, Astron. Astrophys. 194, 250.

Sternberg, A., Dalgarno, A., and Lepp, S. 1987, Astrophys. J. 320, 676.

This article was processed by the author using the TEX macro package from Springer-Verlag. 